CARDIOVASCULAR MEDICINE

\title{
Evaluation of the pattern of treatment, level of anticoagulation control, and outcome of treatment with warfarin in patients with non-valvar atrial fibrillation: a record linkage study in a large British population
}

\author{
M Jones, P McEwan, C LI Morgan, J R Peters, J Goodfellow, C J Currie
}

Heart 2005;91:472-477. doi: 10.1136/hrt.2004.042465

\begin{abstract}
Objective: To evaluate how well patients with non-valvar atrial fibrillation (NVAF) were maintained within the recommended international normalised ratio (INR) target of 2.0-3.0 and to explore the relation between achieved INR control and clinical outcomes.

Design: Record linkage study of routine activity records and INR measurements.

Setting: Cardiff and the Vale of Glamorgan, South Wales, UK.

Participants: 2223 patients with NVAF, no history of heart valve replacement, and with at least five INR measurements.

Main outcome measures: Mortality, ischaemic stroke, all thromboembolic events, bleeding events, hospitalisation, and patterns of INR monitoring.

Results: Patients treated with warfarin were outside the INR target range $32.1 \%$ of the time, with $15.4 \%$ INR values $>3.0$ and $16.7 \%$ INR values $<2.0$. However, the quartile with worst control spent $71.6 \%$ of their time out of target range compared with only $16.3 \%$ out of range in the best controlled quartile. The median period between INR tests was 16 days. Time spent outside the target range decreased as the duration of INR monitoring increased, from $52 \%$ in the first three months of monitoring to $30 \%$ after two years. A multivariate logistic regression model showed that a $10 \%$ increase in time out of range was associated with an increased risk of mortality (odds ratio (OR) 1.29, $p<0.001$ ) and of an ischaemic stroke (OR 1.10, $p=0.006$ ) and other thromboembolic events (OR 1.12, $p<0.001$ ). The rate of hospitalisation was higher when INR was outside the target range. Conclusions: Suboptimal anticoagulation was associated with poor clinical outcomes, even in a well controlled population. However, good control was difficult to achieve and maintain. New measures are needed to improve maintenance anticoagulation in patients with NVAF.
\end{abstract}

See end of article for authors' affiliations

Correspondence to: Dr Craig J Currie, Cardiff Research Consortium, Heath Park, Cardiff CF14 4UJ, UK; curriec@ cardiff.ac.uk

17 September 2004

l: has been estimated that 470000 patients received oral anticoagulation in 2001 in the UK. ${ }^{1}$ This number is likely to increase as the number of people in the elderly population

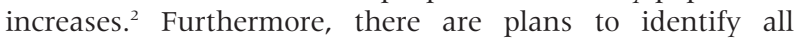
patients with atrial fibrillation (AF) through primary care screening as part of a national stroke prevention strategy implemented in $2004 .^{3}$

Long term anticoagulation treatment of patients with non-valvar atrial fibrillation (NVAF) can reduce the annual risk of stroke by two thirds. ${ }^{45}$ Such treatment compares favourably with the alternative, aspirin treatment. ${ }^{6}$ However, the pharmacokinetic profile of warfarin is complex, ${ }^{7}$ and monitoring is required to avoid both thromboembolic events associated with low intensity anticoagulation and haemorrhagic complications associated with higher intensity. Target levels of oral anticoagulation are disease specific and measured with the international normalised ratio (INR). In the case of NVAF, the range is 2.0-3.0. To attain INR values within this range, patients are routinely monitored and their doses are adjusted when necessary. In practice, it is recognised that long term stability is difficult to achieve because of unexpected fluctuations of the INR values in patients, which can be attributed to numerous factors including change in diet, poor compliance with medication, alcohol consumption, seasonal variation, and drug to drug interactions. ${ }^{7-9}$

The objective of the study was to evaluate how well patients with NVAF were maintained within the recommended
INR target of 2.0-3.0 and to explore the relation between achieved INR control and clinical outcome.

\section{PARTICIPANTS AND METHODS}

\section{Data sources}

Three sets of data routinely collected in the UK were used: inpatient data from April 1995 to March 2000 containing a range of information including discharge diagnosis (International classification of diseases, 10th revision (ICD-10)), length of stay and operative procedures (Office of Population, Censuses and Surveys); haematology laboratory reports dating from June 1995 to January 2002 containing details of INR monitoring test results (including any initiated by a primary care source); and mortality data derived from the UK Office of National Statistics from January 1995 containing information on cause of death (ICD-9). These data underwent a process of record linkage to identify those records relating to the same patient both within and between the contributory datasets by using probability matching algorithms. ${ }^{10}$ The epidemiology of stroke ${ }^{11}$ and heart disease ${ }^{12}$ has been described previously in this same population with virtually identical methods.

Abbreviations: $A F$, atrial fibrillation; $I C D$, International classification of diseases; INR, international normalised ratio; NVAF, non-valvar atrial fibrillation 


\section{Participants}

The study was conducted in Cardiff and the Vale of Glamorgan, a largely urban area of South Wales with a population of 424000 (2001 census). Patients were those identified during the period with a diagnosis of AF (ICD-10 code I48) recorded on inpatient admission and a minimum of five INR recordings before and after their initial NVAF admission. These patients were assumed to be taking oral anticoagulation in the form of warfarin, although no direct data on drugs or dosage were available. Patients were excluded if they had any record of heart valve procedures (appendix 1) before the first recorded AF diagnosis because the target INR range is higher for this indication. ${ }^{7}$

\section{Linear interpolation and target range}

To estimate the proportion of time that a patient was within the normal range, we assumed that the actual difference in INR between any two consecutive measurements was linear, and the data were interpolated accordingly. ${ }^{13}$ Time in target range for each patient was assessed by the percentage of interpolated INR values within the target range of 2.0-3.0.

\section{Statistical analyses}

The patterns of INR testing were analysed by calculating the time in days between consecutive INR tests for each patient. The relation between the intensity of INR and duration of warfarin treatment was investigated by plotting the average percentage of time in range versus the time in months after initial warfarin treatment. Patients who had an INR reading within six weeks of the earliest available data were omitted from this analysis, as it was not possible to determine whether an INR value was a first reading or a subsequent reading.

Multivariate logistic regression was applied to the data to assess whether poor control was associated with mortality and post-AF clinical events-namely, bleeding, thromboembolic events, and ischaemic stroke (appendix 2). All the models included age, sex, and hospital length of stay at first recorded AF admission (an indicator of morbidity at baseline), with the models for clinical events including a term for any pre-AF occurrences of the event. Regression models were then constructed through the individual inclusion of terms relating to different aspects of INR control. The mean INR and the standard deviation of INR terms were related to the raw INR data, with the odds ratios constructed for 0.1 unit changes in INR. We constructed odds ratios for the percentage time in and out of range variables where there was a $10 \%$ change in the variable of interest.

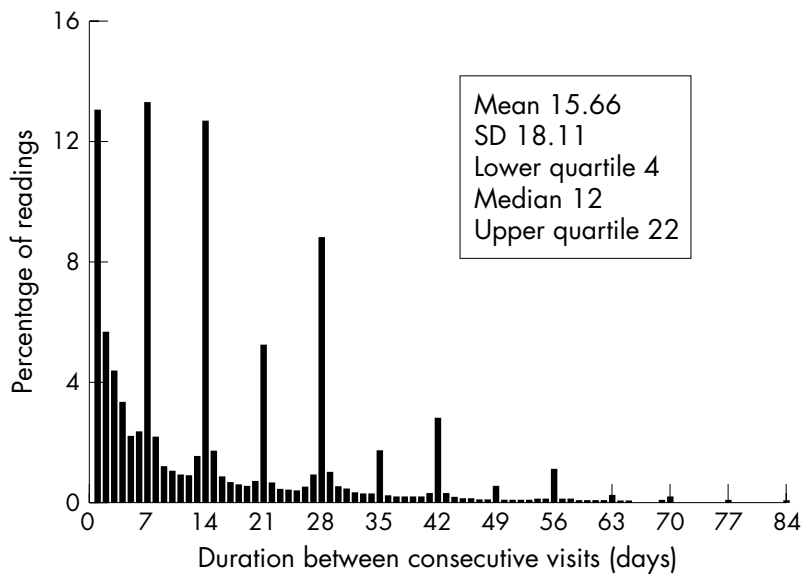

Figure 1 Percentage of international normalised ratio (INR) readings versus time between consecutive INR readings.

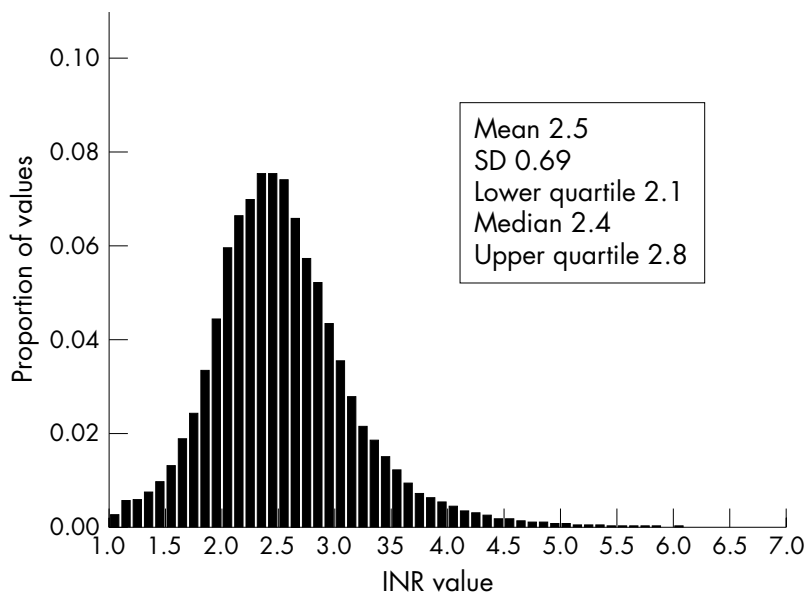

Figure 2 Distribution of interpolated INR values.

\section{RESULTS}

From the 222398 patients hospitalised during the study period we identified 6247 patients with AF and excluded 139 $(2.2 \%)$ on the basis of a history of heart valve surgery. The remainder, 6108, had NVAF; of these patients, 2828 (46.3\%) had any INR reading and 2223 (36.4\%) had more than four INR readings. These 2223 patients constituted the study

Table 1 Key summary statistics for the non-valvar atrial fibrillation (AF) study group

\begin{tabular}{lllllll}
\hline Sex & $\begin{array}{l}\text { Age group } \\
\text { (years) }\end{array}$ & $\begin{array}{l}\text { Number of } \\
\text { patients }\end{array}$ & Mean INR & $\begin{array}{l}\text { Mean LOS } \\
\text { (days) }\end{array}$ & Death* (\%) & $\begin{array}{l}\text { Emergency } \\
\text { readmissiont (\%) }\end{array}$ \\
\hline \multirow{2}{*}{ Men } & $<60$ & 171 & 2.5 & 8.0 & 1.8 & 5.8 \\
& $60-64$ & 150 & 2.5 & 9.2 & 4.7 & 5.3 \\
& $65-70$ & 242 & 2.5 & 8.2 & 3.7 & 5.0 \\
& $71-75$ & 240 & 2.5 & 10.3 & 4.2 & 5.8 \\
& $>75$ & 376 & 2.5 & 12.4 & 9.0 & 3.5 \\
\multirow{4}{*}{ Women } & All ages & 1179 & 2.5 & 10.1 & 5.3 & 4.8 \\
& $<60$ & 57 & 2.6 & 7.6 & 0.0 & 8.8 \\
& $60-64$ & 53 & 2.7 & 7.3 & 1.9 & 7.5 \\
& $65-70$ & 138 & 2.6 & 10.3 & 5.1 & 5.8 \\
& $71-75$ & 217 & 2.6 & 11.2 & 5.5 & 6.5 \\
& $>75$ & 578 & 2.6 & 15.2 & 8.1 & 4.0 \\
& All ages & 1043 & 2.6 & 12.9 & 6.4 & 5.2 \\
\hline
\end{tabular}

*Death within three months of the first recorded AF event.

†Return as inpatients with an emergency admission code within a week of the first recorded AF event.

INR, international normalised ratio; LOS, length of hospital stay at the time of the first recorded AF. 
group, for whom there were 135149 actual INR readings and 2118881 follow up days for which values were calculated. This group had a crude population prevalence of $0.53 \%$ and an age specific prevalence of $4.5 \%$ in those older than 75 years; $53.1 \%$ were men with a mean (SD) age of 69.8 (11.0) years at the time of the first recorded AF event (table 1). The corresponding mean (SD) age for women was 75.6 (9.0) years. No clear relation was evident between age at first recorded AF diagnosis and mean INR; however, average length of hospital stay and the proportion of deaths within three months of the first recorded AF event increased noticeably with increasing age (table 1).

There was a clear pattern of consecutive clinic visits occurring either weekly (13.3\%), bi-weekly (12.7\%), or monthly $(8.8 \%$ ) (fig 1 ). The mean (SD) time between consecutive visits was 15.7 (18.1 days), with a median of 12 days and an interquartile range of 4-22 days. Of the 137507 INR measurements, $46.6 \%$ were outside the target range.

In a plot of interpolated INR values, the distribution of INR intensity is asymmetrical and positively skewed (fig 2). Under these conditions, the mean (SD) INR value was 2.5 (0.69), with a median of 2.4 and an interquartile range of 2.4-2.8. In a plot of interpolated data, patients were outside the target range $32.1 \%$ of the time, with $15.4 \%$ of INR values $>3.0$ and $16.7 \%$ of INR values $<2.0$. However, division of the patients into quartiles based on proportion of time spent in target range highlighted that these average figures disguised a wide variation in the time spent out of target range. On average, patients in the quartile with worst control were out of target range for $71.6 \%$ of the time, as compared with $16.3 \%$ in the best controlled quartile.

Figure 3 shows the relation between the proportion of results within, above, and below the desired INR range of 2.0-3.0 by duration of treatment. The proportion of INR results outside the desired target range decreased as the duration of warfarin treatment increased, ranging from 52\% outside the target range in the first month and decreasing to $30 \%$ after two years of monitoring.

There were 5350 hospital admissions for patients from the study group after the initial admission with a diagnosis of NVAF. The rate of hospitalisation increased the further the INR value deviated from the target range (fig 4). The rates of admission were lowest when the INR value for the day before admission was towards the midpoint of the target range.

Multivariate logistic regression models showed that an increased risk of all cause mortality, ischaemic stroke, and all post-AF thromboembolic events was associated with poor warfarin control measured in various ways (table 2) after

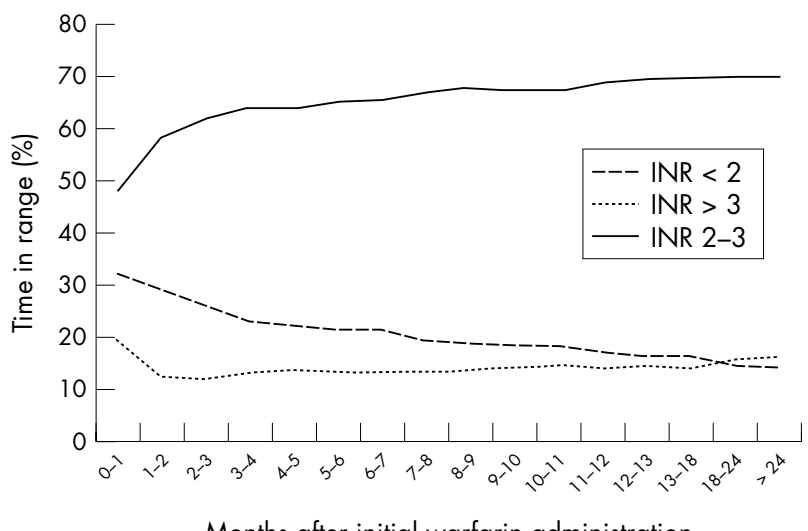

Months after initial warfarin administration

Figure 3 Interpolated INR values in target range (2-3) versus time after start of warfarin treatment.

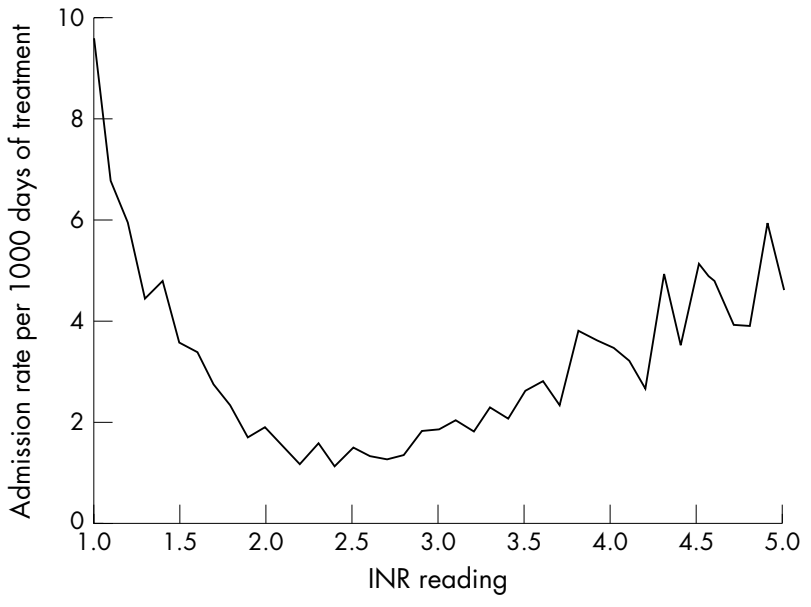

Figure 4 Hospital admission rate as a function of INR level.

adjustment for age, sex, and morbidity at baseline. For example, a $10 \%$ increase in the time out of range was associated with an increase in the risk of mortality of $29 \%$ (odds ratio (OR) 1.29, p < 0.001), an increase of $10 \%$ in the risk of an ischaemic stroke (OR 1.15, p = 0.006), and an increase of $12 \%$ for all thromboembolic events (OR 1.12, $\mathrm{p}<0.001)$. The risk of an admission for a bleeding related event was also associated with a prior bleeding event and with greater variability in INR values as measured by the standard deviation of the INR readings (OR 1.04, p = 0.017).

\section{DISCUSSION}

In the general population, only a minority of patients with NVAF were treated with warfarin, despite its proven efficacy in reducing stroke and other vascular events. There are conflicting guidelines about the use of anticoagulant treatment. ${ }^{14}$ For many patients-for example, those under 65 years without any other complicating factors such as diabetes, hypertension, or previous cerebrovascular eventwarfarin treatment is not considered necessary. ${ }^{15}$ In addition, there are practical barriers to safe warfarin treatment such as the need for constant monitoring of INR values, individual risk of haemorrhage, and patient preferences. ${ }^{16}$

Within the group of patients who were routinely monitored with INR readings-assumed to result from warfarin treatment-almost a third of the treatment time and close to half of the raw INR readings were outside the target range. Even so, this result was rather low compared with those found in other published data, ${ }^{17}{ }^{18}$ possibly reflecting that the centre where this study took place is a university teaching hospital. Patients treated in other, non-academic settings may not achieve this level of control. The quality of care may also relate to the frequency of testing. The patients in our population had INR tests 23 times a year on average, whereas monitoring rates as high as 13 times within three months and as low as six times over a year have been reported. ${ }^{19} 20$ The frequency of testing appears to depend on the local model of anticoagulation and, in addition to the quality of control provided, has direct consequences on the cost of $\mathrm{AF}$ management. ${ }^{21}$

The overall figure for the study group also conceals wide variation in the actual time spent in range by any individual patient. The quartile of patients with the poorest control spent, on average, almost three times as long out of range as the group with the best control. Patients were least likely to die or be admitted to hospital when their INR values were near to the midpoint of the target range. Although, in view of the influence of illness and changes in medication, it would 
Table 2 Logistic regression models evaluating the relation between post-AF clinical outcomes and anticoagulation control

\begin{tabular}{|c|c|c|c|c|c|c|c|c|}
\hline \multirow[b]{2}{*}{ Variable } & \multicolumn{2}{|l|}{ All cause mortality } & \multicolumn{2}{|l|}{ Bleeding events } & \multicolumn{2}{|c|}{ Thromboembolic events } & \multicolumn{2}{|l|}{ Ischaemic strokes } \\
\hline & $\begin{array}{l}\text { OR } \\
(75 \% \mathrm{Cl})\end{array}$ & $p$ Value & $\begin{array}{l}\text { OR } \\
(75 \% \mathrm{Cl})\end{array}$ & $p$ Value & $\begin{array}{l}\text { OR } \\
(75 \% \mathrm{Cl})\end{array}$ & $\mathrm{p}$ Value & $\begin{array}{l}\text { OR } \\
(75 \% \mathrm{Cl})\end{array}$ & p Value \\
\hline Age & $\begin{array}{l}1.057 \\
(1.045 \text { to } 1.070)\end{array}$ & $0.000^{*}$ & $\begin{array}{l}1.029 \\
(1.008 \text { to } 1.051)\end{array}$ & $0.017^{*}$ & $\begin{array}{l}1.026 \\
(1.012 \text { to } 1.040)\end{array}$ & $0.000^{*}$ & $\begin{array}{l}1.020 \\
(1.003 \text { to } 1.037)\end{array}$ & $0.001^{*}$ \\
\hline Sex & $\begin{array}{l}0.842 \\
(0.689 \text { to } 1.029)\end{array}$ & 0.158 & $\begin{array}{l}0.593 \\
(0.394 \text { to } 0.893)\end{array}$ & $0.008^{*}$ & $\begin{array}{l}0.976 \\
(0.754 \text { to } 1.263)\end{array}$ & 0.882 & $\begin{array}{l}1.071 \\
(0.780 \text { to } 1.470)\end{array}$ & 0.727 \\
\hline Length of stay & $\begin{array}{l}1.015 \\
(1.009 \text { to } 1.021)\end{array}$ & $0.000^{*}$ & $\begin{array}{l}1.007 \\
(0.996 \text { to } 1.017)\end{array}$ & 0.262 & $\begin{array}{l}1.008 \\
(1.001 \text { to } 1.015)\end{array}$ & $0.036^{*}$ & $\begin{array}{l}1.012 \\
(1.004 \text { to } 1.019)\end{array}$ & $0.003^{*}$ \\
\hline Pre-AF bleeding & NA & NA & $\begin{array}{l}2.571 \\
(1.186 \text { to } 5.573)\end{array}$ & $0.031^{*}$ & NA & NA & NA & NA \\
\hline Pre-AF thromboembolic event & NA & NA & NA & NA & $\begin{array}{l}1.501 \\
(1.017 \text { to } 2.214)\end{array}$ & $0.048^{*}$ & NA & NA \\
\hline Pre-AF stroke & NA & NA & NA & NA & NA & NA & $\begin{array}{l}3.397 \\
(2.063 \text { to } 5.594)\end{array}$ & $0.000^{*}$ \\
\hline + Mean INR† & $\begin{array}{l}1.049 \\
(1.025 \text { to } 1.073)\end{array}$ & $0.000^{*}$ & $\begin{array}{l}1.017 \\
(0.974 \text { to } 1.061)\end{array}$ & 0.460 & $\begin{array}{l}0.955 \\
(0.924 \text { to } 0.987)\end{array}$ & $0.004^{*}$ & $\begin{array}{l}0.942 \\
(0.904 \text { to } 0.982)\end{array}$ & $0.003^{*}$ \\
\hline + SD INR† & $\begin{array}{l}1.087 \\
(1.064 \text { to } 1.110)\end{array}$ & $0.000^{*}$ & $\begin{array}{l}1.040 \\
(1.010 \text { to } 1.072)\end{array}$ & $0.017^{*}$ & $\begin{array}{l}1.004 \\
(0.980 \text { to } 1.029)\end{array}$ & 0.747 & $\begin{array}{l}1.002 \\
(0.973 \text { to } 1.033)\end{array}$ & 0.879 \\
\hline$+\%$ in target range $\neq$ & $\begin{array}{l}0.774 \\
(0.738 \text { to } 0.811)\end{array}$ & $0.000^{*}$ & $\begin{array}{l}0.945 \\
(0.865 \text { to } 1.033)\end{array}$ & 0.218 & $\begin{array}{l}0.891 \\
(0.842 \text { to } 0.942)\end{array}$ & $0.000^{*}$ & $\begin{array}{l}0.905 \\
(0.844 \text { to } 0.970)\end{array}$ & $0.006^{*}$ \\
\hline$+\%$ irregular $(<2.0) \ddagger$ & $\begin{array}{l}1.172 \\
\text { (1.119 to } 1.228)\end{array}$ & $0.000^{*}$ & $\begin{array}{l}1.008 \\
(0.917 \text { to } 1.107)\end{array}$ & 0.876 & $\begin{array}{l}1.148 \\
(1.088 \text { to } 1.212)\end{array}$ & $0.000^{*}$ & $\begin{array}{l}1.146 \\
(1.074 \text { to } 1.223)\end{array}$ & $0.000^{*}$ \\
\hline$+\%$ irregular $(>3.0) \ddagger$ & $\begin{array}{l}1.217 \\
(1.143 \text { to } 1.296)\end{array}$ & $0.000^{*}$ & $\begin{array}{l}1.097 \\
(0.977 \text { to } 1.232)\end{array}$ & 0.134 & $\begin{array}{l}0.948 \\
(0.867 \text { to } 1.036)\end{array}$ & 0.229 & $\begin{array}{l}0.903 \\
(0.802 \text { to } 1.017)\end{array}$ & 0.079 \\
\hline$+\%$ out of target rangef & $\begin{array}{l}1.293 \\
(1.233 \text { to } 1.355)\end{array}$ & $0.000^{*}$ & $\begin{array}{l}1.058 \\
(0.968 \text { to } 1.156)\end{array}$ & 0.218 & $\begin{array}{l}1.123 \\
(1.061 \text { to } 1.188)\end{array}$ & $0.000^{*}$ & $\begin{array}{l}1.105 \\
(1.031 \text { to } 1.184)\end{array}$ & $0.006^{*}$ \\
\hline
\end{tabular}

*Significant at the $5 \%$ level; $† 0.1$ unit change in the actual INR value; $\ddagger 10 \%$ change in specified range.

$\mathrm{Cl}$, confidence interval; NA, not applicable; OR, odds ratio.

be overly simplistic to assume a direct relation between a point INR result and overall outcomes, this may tend to confirm the target range as the optimal level of anticoagulation in NVAF.

Because of the inherent difficulty in maintaining control at the individual level, characterising what we mean by poor control in these patients was in itself difficult from a mathematical perspective. We investigated measurement of poor control through a number of alternative parameters in multivariate analysis, standardising for age, sex, and baseline morbidity. All of the selected measurements were associated with poor outcome.

Even in this group of patients, who at a population level appear to have good control, instability of INR values has significant implications for mortality and other clinical outcomes. We have shown an association between INR values outside the target range and increased rate of hospitalisation. In addition we have shown that a $10 \%$ increase in the amount of time out of range is associated with an increase in the likelihood of death of $29.3 \%$ and increased the probability of a thromboembolic event by $12.4 \%$, confirming previous findings. ${ }^{12}$ Since INR control was worst during the first three months after the initiation of warfarin and poor control was linked to an increased risk of events, it was likely that patients were at higher risk of events during their first months of treatment while an appropriate dose of warfarin was being established. However, some patients were anticoagulated after an index stroke event, which in itself predicts future stroke events. ${ }^{13}$ The improvements in time spent in range that occur over time may in part be caused by the withdrawal from treatment of patients who have the greatest difficulty with warfarin treatment, either in control or adverse events.

There were limitations to this study. No data were available describing medication including warfarin or warfarin dosage. Because of this we assumed that only patients who had some degree of continuous monitoring ( $>4$ INR observations) were treated with warfarin. We were unable to control for confounding factors including other medications and co-morbidities where that information was primarily held in primary care records. The lack of primary care health records also prevented us stratifying patients by their underlying risk of stroke, although it has been calculated that as few as $6 \%$ of patients with $\mathrm{AF}$ are at low risk of stroke. ${ }^{22}$ Furthermore, only patients who had an inpatient diagnosis of NVAF were included. Patients with AF diagnosed in primary care could not be identified; therefore, the patients included in the study may have greater morbidity than a sample selected from both the hospital and community. There are also methodological issues when attempting to estimate the proportion of time a patient is within or outside the target INR range. ${ }^{1}$ The assumption that INR values change in a linear fashion is unlikely to be the case. Values may change sharply soon after a reading has been taken as a result of treatment management or before a reading that has been initiated by a clinical event. As a result extreme values of INR may lead to a bias, as the time spent at either extreme is overestimated. However, the proportion of measurements at these extreme values would be small ${ }^{13}$ and linear interpolation has been shown to be the simplest and most valid technique compared with other methods. ${ }^{23}$ Given these limitations, these data describe the care and monitoring of a large cohort of patients, with a very large number of INR values over a lengthy study period.

To conclude, suboptimal anticoagulation was associated with poor clinical outcomes; however, good control is difficult to achieve and maintain. New measures are needed to improve maintenance anticoagulation in patients with NVAF.

\section{ACKNOWLEDGEMENTS}

This study was funded by AstraZeneca UK.

\section{Authors' affiliations}

M Jones, P McEwan, School of Mathematics, Cardiff University, Cardiff, UK

C Ll Morgan, School of Medicine, Cardiff University, Heath Park, Cardiff, UK 
J R Peters, C J Currie, Department of Medicine, University of Wales College of Medicine, Cardiff, UK

J Goodfellow, Department of Cardiology, University of Wales College of Medicine

Although all of the authors have academic appointments, this work was commissioned in their university spinout company, Cardiff Research Consortium Limited. CRC undertakes applied research for the pharma industry and has worked for a wide range of companies.

\section{APPENDIX 1}

Office of Population, Censuses and Surveys (OPCS) codes used to identify the heart valve procedures in the study

OPCS
code Description

\section{Heart valve procedures}

K25 Plastic repair of mitral valve

K26 Plastic repair of aortic valve

K27 Plastic repair of tricuspid valve

K28 Plastic repair of pulmonary valve

K29 Plastic repair of unspecified valve of heart

K30 Revision of plastic repair of valve of heart

K31 Open incision of valve of heart

K32 Closed incision of valve of heart

K34 Other open operations on valve of heart

K35 Therapeutic transluminal operations on valve of heart

K37 Removal/obstruction from structure adjacent/valve heart

K38

\section{APPENDIX 2}

International classification of diseases, 10 revision (ICD10) codes used to identify the serious adverse events in this study

\begin{tabular}{|c|c|}
\hline $\begin{array}{l}\text { ICD-10 } \\
\text { code }\end{array}$ & Description \\
\hline \multicolumn{2}{|c|}{ Myocardial infarction } \\
\hline 1210 & Acute transmural myocardial infarction of anterior wall \\
\hline 1211 & Acute transmural myocardial infarction of inferior wall \\
\hline 1212 & Acute transmural myocardial infarction of other sites \\
\hline 1213 & Acute transmural myocardial infarction of unspecified site \\
\hline 1214 & Acute subendocardial myocardial infarction \\
\hline 1219 & Acute myocardial infarction, unspecified \\
\hline 1220 & Subsequent myocardial infarction of anterior wall \\
\hline 1221 & Subsequent myocardial infarction of inferior wall \\
\hline 1228 & Subsequent myocardial infarction of other sites \\
\hline 1229 & Subsequent myocardial infarction of unspecified site \\
\hline \multicolumn{2}{|c|}{ Deep vein thrombosis } \\
\hline 1802 & $\begin{array}{l}\text { Phlebitis/thrombophlebitis of other deep vessels low } \\
\text { extremities }\end{array}$ \\
\hline \multicolumn{2}{|c|}{ Pulmonary embolism } \\
\hline 1260 & Pulmonary embolism with mention of acute cor pulmonale \\
\hline 1269 & $\begin{array}{l}\text { Pulmonary embolism without mention of acute cor } \\
\text { pulmonale }\end{array}$ \\
\hline \multicolumn{2}{|l|}{ Bleeding } \\
\hline K226 & $\begin{array}{l}\text { Gastro-oesophageal laceration-haemorrhage syndrome } \\
\text { (Mallory-Weiss syndrome) }\end{array}$ \\
\hline K250 & Gastric ulcer, acute with haemorrhage \\
\hline K252 & $\begin{array}{l}\text { Gastric ulcer, acute with both haemorrhage and } \\
\text { perforation }\end{array}$ \\
\hline K254 & Gastric ulcer, chronic or unspecified with haemorrhage \\
\hline $\mathrm{K} 260$ & Duodenal ulcer, acute with haemorrhage \\
\hline K262 & $\begin{array}{l}\text { Duodenal ulcer, acute with both haemorrhage and } \\
\text { perforation }\end{array}$ \\
\hline K264 & Duodenal ulcer, chronic or unspecified with haemorrhage \\
\hline K270 & Peptic ulcer, acute with haemorrhage \\
\hline K272 & Peptic ulcer, acute with both haemorrhage and perforation \\
\hline K274 & Peptic ulcer, chronic or unspecified with haemorrhage \\
\hline K280 & Gastrojejunal ulcer, acute with haemorrhage \\
\hline K284 & $\begin{array}{l}\text { Gastrojejunal ulcer, chronic or unspecified with } \\
\text { haemorrhage }\end{array}$ \\
\hline
\end{tabular}

Continued

\begin{tabular}{|c|c|}
\hline $\begin{array}{l}\text { ICD-10 } \\
\text { code }\end{array}$ & Description \\
\hline K922 & Gastrointestinal haemorrhage, unspecified \\
\hline M250 & Haemarthrosis \\
\hline R040 & Epistaxis \\
\hline R041 & Haemorrhage from throat \\
\hline R042 & Haemoptysis \\
\hline R048 & Haemorrhage from other sites in respiratory passages \\
\hline R049 & Haemorrhage from respiratory passages, unspecified \\
\hline R58X & Haemorrhage, not elsewhere classified \\
\hline T792 & Traumatic secondary and recurrent haemorrhage \\
\hline N026 & Recurrent and persistent haematuria, dense deposit disease \\
\hline N028 & Recurrent and persistent haematuria, other \\
\hline N029 & Recurrent and persistent haematuria, unspecified \\
\hline R31X & Unspecified haematuria \\
\hline 1610 & Intracerebral haemorrhage in hemisphere, subcortical \\
\hline 1611 & Intracerebral haemorrhage in hemisphere, cortical \\
\hline 1612 & Intracerebral haemorrhage in hemisphere, unspecified \\
\hline 1613 & Intracerebral haemorrhage in brain stem \\
\hline 1614 & Intracerebral haemorrhage in cerebellum \\
\hline 1615 & Intracerebral haemorrhage, intraventricular \\
\hline 1616 & Intracerebral haemorrhage, multiple localised \\
\hline 1618 & Other intracerebral haemorrhage \\
\hline 1619 & Intracerebral haemorrhage, unspecified \\
\hline 1620 & Subdural haemorrhage (acute) (non-traumatic) \\
\hline 1621 & Non-traumatic extradural haemorrhage \\
\hline 1629 & Intracranial haemorrhage (non-traumatic), unspecified \\
\hline Stroke & \\
\hline G450 & Vertebrobasilar artery syndrome \\
\hline G451 & Carotid artery syndrome (hemispheric) \\
\hline G452 & Multiple and bilateral precerebral artery syndromes \\
\hline G453 & Amaurosis fugax \\
\hline G454 & Transient global amnesia \\
\hline G458 & $\begin{array}{l}\text { Other transient cerebral ischaemic attacks and related } \\
\text { syndromes }\end{array}$ \\
\hline G459 & Transient cerebral ischaemic attack, unspecified \\
\hline G460A & Middle cerebral artery syndrome \\
\hline G461A & Anterior cerebral artery syndrome \\
\hline G462A & Posterior cerebral artery syndrome \\
\hline G463A & Brain stem stroke syndrome \\
\hline G464A & Cerebellar stroke syndrome \\
\hline G465A & Pure motor lacunar syndrome \\
\hline G466A & Pure sensory lacunar syndrome \\
\hline G467A & Other lacunar syndromes \\
\hline G468A & $\begin{array}{l}\text { Other vascular syndromes of brain in cerebrovascular } \\
\text { diseases }\end{array}$ \\
\hline 1630 & $\begin{array}{l}\text { Cerebral infarction due to thrombosis of precerebral } \\
\text { arteries }\end{array}$ \\
\hline 1631 & Cerebral infarction due to embolism of precerebral arteries \\
\hline 1632 & $\begin{array}{l}\text { Cerebral infarction due to unspecified occlusion or stenosis } \\
\text { of precerebral arteries }\end{array}$ \\
\hline 1633 & Cerebral infarction due to thrombosis of cerebral arteries \\
\hline 1634 & Cerebral infarction due to embolism of cerebral arteries \\
\hline 1635 & $\begin{array}{l}\text { Cerebral infarction due to unspecified occlusion or stenosis } \\
\text { of cerebral arteries }\end{array}$ \\
\hline 1636 & $\begin{array}{l}\text { Cerebral infarction due to cerebral venous thrombosis, } \\
\text { non-pyogenic }\end{array}$ \\
\hline 1638 & Other cerebral infarction \\
\hline 1639 & Cerebral infarction, unspecified \\
\hline $164 X$ & Stroke, not specified as haemorrhage or infarction \\
\hline 1650 & Occlusion and stenosis of vertebral artery \\
\hline 1651 & Occlusion and stenosis of basilar artery \\
\hline 1652 & Occlusion and stenosis of carotid artery \\
\hline 1653 & $\begin{array}{l}\text { Occlusion and stenosis of multiple and bilateral precerebral } \\
\text { arteries }\end{array}$ \\
\hline 1658 & Occlusion and stenosis of other precerebral artery \\
\hline 1659 & Occlusion and stenosis of unspecified precerebral artery \\
\hline 1660 & Occlusion and stenosis of middle cerebral artery \\
\hline 1661 & Occlusion and stenosis of anterior cerebral artery \\
\hline 1662 & Occlusion and stenosis of posterior cerebral artery \\
\hline 1663 & Occlusion and stenosis of cerebellar arteries \\
\hline 1664 & $\begin{array}{l}\text { Occlusion and stenosis of multiple and bilateral cerebral } \\
\text { arteries }\end{array}$ \\
\hline 1668 & Occlusion and stenosis of other cerebral artery \\
\hline 1669 & Occlusion and stenosis of unspecified cerebral artery \\
\hline 1678 & Other specified cerebrovascular diseases \\
\hline $1688 \mathrm{~A}$ & $\begin{array}{l}\text { Other cerebrovascular disorders in diseases classified } \\
\text { elsewhere }\end{array}$ \\
\hline 1693 & Sequelae of cerebral infarction \\
\hline
\end{tabular}




\section{REFERENCES}

1 Fitzmaurice DA, Machin SJ. Recommendations for patients undertaking self management of oral anticoagulation. BMJ 2001;323:985-9.

2 Chatap G, Giraud K, Vincent JP. Atrial fibrillation in the elderly: facts and management. Drugs Aging 2002;19:819-46.

3 Department of Health. National framework for older people. Standard 5: stroke. London: Stationery Office, 2001.

4 EAFT Study Group. Secondary prevention in non-rheumatic atrial fibrillation after transient ischaemic attack or minor stroke. EAFT (European atrial fibrillation trial) Study Group. Lancet 1993;342:1255-62.

5 Atrial Fibrillation Investigators. Risk factors for stroke and efficacy of antithrombotic therapy in atrial fibrillation: analysis of pooled data from five randomised controlled trials. Arch Intern Med 1994; 154:1449-57.

6 Van Walraven C, Gart RG, Singer DE, et al. Oral anticoagulants vs. aspirin in nonvalvular atrial fibrillation: an individual patient meta-analysis. JAMA 2002;288:2441-8.

7 Hirsh J, Fuster V, Ansell J, et al. American Heart Association/American College of Cardiology Foundation guide to anticoagulation therapy. Circulation 2003;107:1692-711.

8 Hylek EM, et al. Acetaminophen and other risk factors for excessive warfarin anticoagulation. JAMA 1998;279:657-62.

9 Salobir B, Sabovic M, Peternel P. Intensity of long-term treatment with warfarin is influenced by seasonal variations. Pathophysiol Haemost Thromb 2002; $32: 151-4$

10 Gill L, Goldacre M, Simmons $H$, et al. Computerised linking of medical records: methodological guidelines. J Epidemiol Commun Health 1993:47:316-9.

11 Currie CJ, Morgan CL, Gill L, et al. The epidemiology and costs of acute hospital care for cerebrovascular disease in diabetic and non-diabetic populations. Stroke 1997;28:1142-6.
12 Currie CJ, Morgan CL, Peters JR. Patterns and costs hospital care for coronary heart disease relate and not related to diabetes. Heart 1997;78:544-9.

13 Rosendaal FR, Cannegieter SC, van der Meer FJM, et al. A method to determine the optimal intensity of oral anticoagulant therapy. Thomb Haemost 1993;69:236-9.

14 Thomson R, McElroy, Sudlow M. Guidelines on the anticoagulant treatment in atrial fibrillation in Great Britain: variation in content and implication s for treatment. BMJ 1998;316:509-13.

15 Lip GYH, Hart RG, Conway DSG. ABC of antithrombotic therapy: antithrombotic therapy for atrial fibrillation. BMJ 2002;325:1022-5.

16 Buckingham TA, Hatala R. Anticoagulants for atrial fibrillation: why is the treatment rate so low? Clin Cardiol 2002;25:447-54

17 Cromheeke ME, Levi $M$, Colly LP, et al. Oral anticoagulation self-management and management by specialist anticoagulation clinic: a randomised crossover comparison. Lancet 2000;356:97-102.

18 Kahlra L, Yu G, Perez I, et al. Prospective cohort study to determine if trial efficacy of anticoagulation for stroke prevention in atrial fibrillation translates into clinical effectiveness. BMJ 2000;320:1236-9.

19 Fitzmaurice DA, Murray ET, Gee KM, et al. Does the Birmingham model of oral anticoagulation management in primary care work outside trial conditions? Br J Gen Pract 2001;51:828-9.

20 Wilson SJA, Wells PS, Kovacs MJ, et al. Comparing the quality of oral anticoagulation clinics and by family physicians: a randomized controlled trial. CMAJ 2003;169:293-8.

21 Stewart S, Murphy N, Walker A, et al. Cost of an emerging epidemic: an economic analysis of atrial fibrillation in the UK. Heart 2004;90:286-92.

22 Wang TJ, Massaro JM, Levy D, et al. A risk score for predicting stroke or death in individuals with new-onset atrial fibrillation in the community: the Framingham heart study. JAMA 2003;290:1049-56.

23 Hutten BA, Prins MH, Redekop WK, et al. Comparison of three methods to assess therapeutic quality control of treatment with vitamin $\mathrm{K}$ antagonists. Thromb Haemost 1999:82:1260-3.

\section{IMAGES IN CARDIOLOGY}

\section{Cardiovascular magnetic resonance of left ventricular pseudoaneurysm}

A

60 year old woman presented with an inferolateral myocardial infarction (MI) which was treated with thrombolytics and complicated by heart failure. Transthoracic echocardiography identified a large left ventricular (LV) pseudoaneurysm and coronary angiography demonstrated an occluded circumflex artery. Cardiovascular magnetic resonance (CMR) was performed before surgery. CMR showed a $5.7 \mathrm{~cm} \times$ $8 \mathrm{~cm} \times 10 \mathrm{~cm}$ (right-to-left by anteroposterior by cephalad-caudad) posterolateral LV pseudoaneurysm with a wide neck in free communication with the basal LV cavity (panels A-C). The pseudoaneurysm split the wall between the posterior mitral valve leaflet (PMVL) and its supporting papillary muscle. Cine images showed reduced long axis function and there was thinning and akinesis of the remaining basal anterolateral and inferolateral wall (to view video clip visit the Heart website-http://www.heartjnl.com/ supplemental). Early gadolinium enhanced CMR detected thrombus within the pseudoaneurysm while late gadolinium enhanced CMR demonstrated enhancement within the wall of the pseudoaneurysm and surrounding akinetic segments indicative of MI. This case illustrates the role of CMR with gadolinium enhancement for providing valuable structural and functional information in
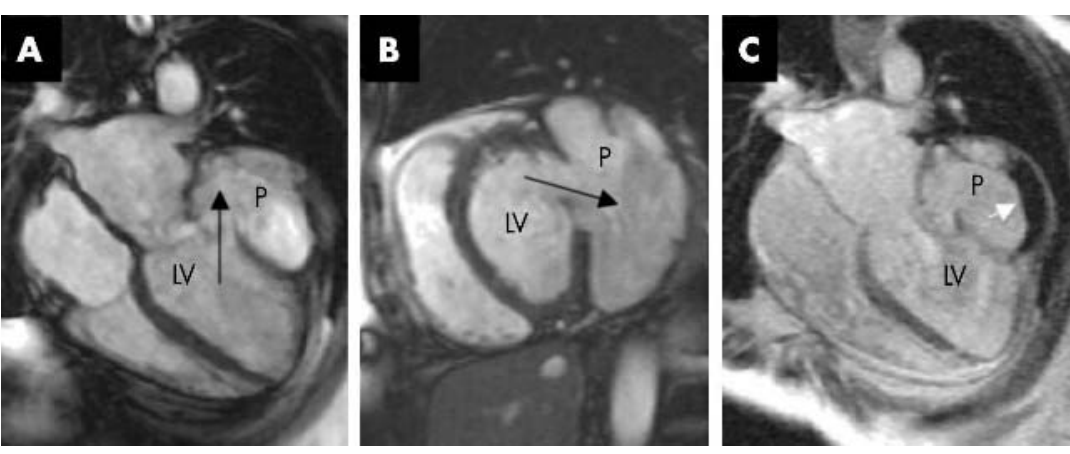

Pre-operative cardiovascular magnetic resonance (CMR) showing left ventricular pseudoaneurysm in four chamber (A) and basal short axis (B) views. The neck of the pseudoaneurysm measured approximately $2 \mathrm{~cm} \times 3 \mathrm{~cm}$ and the directionality of flow from the left ventricle is represented by the black arrows. Early gadolinium enhanced CMR identified thrombus within the wall of the pseudoaneurysm (C, four chamber view, white arrow). LV, left ventricle; P, pseudoaneurysm.

the pre-operative assessment of LV pseudo-

aneurysms.

\section{A Varghese \\ J Pepper \\ D J Pennell}

a.varghese@rbh.nthames.nhs.uk

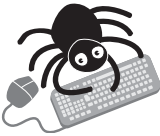

To view video clip visit the Heart websitehttp://www.heartjnl.com/supplemental 